\title{
Perilaku Konsumsi Masyarakat Modern Perspektif Islam: Telaah Pemikiran Imam Al-Ghazali dalam Ihya' Ulumuddin
}

\author{
Elvan Syaputra \\ Alumnus Program Master of Muamalat Administration, \\ Fakulti Ekonomi dan Muamalat (FEM), Universiti Sains Islam Malaysia. \\ E-mail: elvansyaputra@gmail.com
}

\begin{abstract}
Satisfaction in fulfilling what someone want to consume is the measure of happiness. Such shopping now becomes an endless human need. Herein lies the consumption in the sense of altering "consumption as necessary" into "consumption as wants". In this case, it is intended that one's motivation for spending is no longer to meet basic human needs, but rather to relate to their identity. This proves that the culture of consumerism has changed the pattern of people's dependence in consume. This study aims to conduct an in-depth analysis of the pattern of consumption of modern society in terms of Islam; especially Imam al-Ghazali in Ihya 'Ulumuddin. The conclusion of this study is that AlGhazali laid the foundation of a Muslim's life by attaining the goal of the salvation of the hereafter. As for one way to achieve the purpose of the Hereafter by running the consumption activity based on Islamic sharia.
\end{abstract}

Keywords: consumption behavior, al-Ghazali, Islamic consumption behavior.

\section{Pendahuluan}

Jika Rane Descartes menyatakan bahwa, "Aku berpikir, maka aku ada"(Cogito Ergo Sum)1; yang menjadi kebanggaan atas eksistensi manusia berdasarkan rasionalitas semata. Maka istilah yang dominan dan tak kalah penting akhir-akhir ini adalah "Aku belanja, maka aku ada" (Emo Ergo Sum) sebuah

${ }^{1}$ Aku berpikir maka aku ada. kalimat ini membuktikan bahwa satu-satunya hal yang pasti di dunia ini adalah keberadaan seseorang sendiri. Keberadaan ini bisa dibuktikan dengan fakta bahwa ia bisa berpikir sendiri. Ali Mudhofir, Kamus Filsafat Barat, 125 
peneguhan eksistensial manusia yang terkadang tanpa dasar nalar. ${ }^{2}$ Proses inilah yang cakap terjadi dan berimplikasi kepada sifat konsumsi berlebihan, sehingga konsumsi tidak lagi hanya sebatas membeli untuk mengkonsumsi, namun kini kian bergeser dengan apa yang disebut sebagai gaya hidup(Lifestyle) atau cara hidup(Way of life $)^{3}$. Kecendrungan masyarakat akan konsumsi sebenarnya sangat dipengaruhi oleh factor kebahagiaan, yang membawanya menuju pada objek yang memberinya kepuasan(Satisfaction $)^{4}$. Kepuasan dalam memenuhi apa yang ingin dikonsumsi adalah hasrat dalam berekonomi yang sekarang menjadi tolak ukur kebahagian seseorang. ${ }^{5}$ Berbelanja contohnya, saat ini belanja menjadi kebutuhan manusia yang tak ada habisnya. Disinilah letak konsumsi dalam arti mengubah "konsumsi seperlunya" menjadi konsumsi mengada-ngada. ${ }^{6}$ Dalam hal ini dimaksudkan bahwa motivasi seseorang untuk belanja tidak lagi guna memenuhi kebutuhan dasar sebagai manusia, melainkan terkait dengan hal lain, yaitu Identitas. Orang membeli makanan bukan lagi bertujuan untuk memenuhi kebutuhan alaminya, terlepas masalah harga atau lapar, akan tetapi yang dimaksud disini adalah dia merasa lebih baik dan bahagia apabila dapat makan direstoran ternama daripada di warung biasa.

Hal Ini membuktikan bahwa budaya konsumerisme telah merubah pola kehidupan menjadi ketergantungan masyarakat dalam berkonsumsi. ${ }^{7}$ Masyarakat saat ini dikelilingi oleh factor konsumsi yang mencolok dengan multiplikasi objek, jasa, dan material. ${ }^{8}$ Yang menjadikan masyarakat tidak pernah puas secara actual, alhasil, sebuah produk tidak lagi mengarah pada fungsi kebutuhan, melainkan pada apa yang diebut logika hasrat(a logic of desire) sehingga mempengaruhi tata nilai, sosial, kultur masyarakat dan gaya hidup mereka. ${ }^{9}$ Dalam hal ini, tata nilai yang sangat dominan diletakan sebagai regulator kehidupan guna mencegah kerusakan yang ditimbulkan oleh tingkah laku manusia

\footnotetext{
${ }^{2}$ Haryanto Soedjatmiko, Saya berbelanja Maka Saya Ada: Ketika Konsumsi dan Desain Menjadi Gaya Hidup Konsumeris (Yogyakarta: Jalasutra, 2008), 2

${ }^{3}$ QS Al-Ahqaf:20, QS Al-Furqon:67, QS Al-Isra: 29, lihat: Haryanto Soedjatmiki, "Saya berbelanja maka saya ada, ketika konsumsi dan desain menjadi gaya hidup konsumeris, h.IV, lihat juga: Muhammad, Prinsip-prinsip Ekonomi Islam,(Yogyakarta: Graha Ilmu, 2007), 60

4 Jean Baudrillard, Masyarakat Konsumsi, Alih bahasa dari La Societe de Consummation, Oleh: Wahyunto ( Jakarta, Kreasi Wacana, 2004), 73. Lihat juga Muhammad dan Alimin, Etika \& Perlindungan Konsumen Dalam Ekonomi Islam, (Yogyakarta: BPFE Fakultas Ekonomi UGM, 2004), 79.

${ }^{5}$ Ibid, Jean Baudrillard, Masyarakat Konsumsi, 79

${ }^{6}$ Afzalur Rahman, Qur'anic Science, terj. Taufik Rahman, dengan Judul Ensiklopediana Ilmu Dalam Al-Qur'an; Rujukan terlengkap Isyarat-isyarat ilmiah dalam Al-Qur'an, (Bandung: PT Mizan Pustaka, 2007), 229

${ }^{7}$ Hal ini dimaksudkan realita masyarakat yang luar biasa tentang konsumsi dan kelimparuahan ang dibentuk oleh melimpahnya objek, jasa, barang-barang material yang kemudian membentuk sejenis mutasi fundamental dalam ekologi kemanusian. Makna sebenarnya bahwa orang-orang kaya tidak lagi dikelilingi oleh orang lain, tetapi dikelilingi oleh objek. (Jean Baudrillard, Masyarakat Konsumsi, Alih bahasa dari La Societe de Consummation, Oleh: Wahyunto. 3

${ }^{8}$ Ibid, 230

${ }^{9}$ Josept A Schumpeter, Capitalism, Socialism and Democarcy, (New York: Harper \& Brothers Publishers, 1942), 12
} 
yang cenderung egoistis dan liar adalah Etika. ${ }^{10}$ Etika sebagai kaidah yang dapat menjadi tolak ukur sebuah nilai kebajikan dan keburukan, kebenaran dan kebathilan, kesempurnaan dan kekurangan khususnya dalam hal berkonsumsi. ${ }^{11}$ Etika pada intinya merupakan gambaran atau studi kritis tentang prilaku manusia yang memiliki sifat humanistic ${ }^{12}$ dan rasionalistik $^{13}$. Seperti halnya etika yang dijelaskan dalam Al-Qur'an lebih banyak menjelaskan tentang nilai-nilai kebaikan dan kebenaran baik pada tataran niat atau ide hingga prilaku dan perangai. Hal ini lebih tegas lagi bila dilihat dari sikap dan prilaku Rasulullah yang digambarkan dalam Al-Qur'an sebagai yang memiliki ahlak yang agung. ${ }^{14}$ Berangkat dari problematika diatas Imam Al-Ghazali memberikan penjelasan yang kritis terhadap problematika konsumsi. Dalam menjelaskan konsep ini, Al-Ghazali memadukan dan mentranformasikan ide-ide luhur sufistik dan menjadikannya sebagai bagian integral dalam masyarakat sehingga dapat membersihkan diri dari unsur-unsur yang tidak Islami.

\section{Tinjauan Historis dan Sosiologis Latar Belakang Kehidupan Imam Al- Ghazali}

Dalam rangka menyingkap lebih dalam misteri pemikiran seorang inherent pemaparan mengenai setting Histories-nya menjadi keharusan. Dalam hal ini penulis menggaris bawahi bahwa lingkungan yang menjadi tempat tinggal sesorang dan masyarakat berada, ikut mempengaruhi proses aktualisasi normanorma dalam kehidupan praktis dan sosial. ${ }^{15}$ Keterkaitan antara dimensi intele ktual dan praktikal, antara teori dan praktis, sebenarnya lebih mewarnai corak pemikiran seseorang pasti selalu berasal based on historal problem. Oleh karena itu konteks lingkungan cukup strategis untuk diabstaraksikan. Al-Ghazali adalah seorang pemikir yang unik dalam sejarah intelektual Islam. Ia adalah seorang faqih, teolog, folosof dan sufi. Bahkan gelar Hujjatul Islam adalah berkat prestasi Tahafut al-falasifah dan Ihya Ulumu Ad-din selalu melekat dengan kebesarannya. ${ }^{16}$ Al-Ghazali terlahir dengan nama lengkap Abu Hamid Ahmad Ibn Muhammad Al-Ghazali at-Thusi, Al-Ghazali yang pada waktu itu telahir pada

\footnotetext{
${ }^{10}$ Badroen Faishal, Etika Bisnis Dalam Islam, (Jakarta: Kencana, 2007), 2

${ }^{11}$ Suparman Syukur, Etika Religius, (Yogyakarta: Pustaka Pelajar, 2004), 3

12 Humanistik dalam pengertian ini mengarahkan manusia pada pencapaian hakekat kemanusiaan yang tertinggi dan tidak bertentangan dengan fitrah manusia itu sendiri.

13 Rasionalistik dalam hal bahwa semua pesan-pesan yang diajarkan al-Qur'an terhadap manusia sejalan dengan prestasi rasionalitas manusia yang tertuang dalam karya-karya para filosof, seperti ajakan kepada kebenaran, keadilan, kejujuran.

${ }^{14}$ Muhammad \& Lukman Fauroni, Visi Al-Qur'an Tentang Etika dan Bisnis, (Jakarta: Selemba Diniyah, 2002), 40

${ }^{15}$ Amin Abdullah, Dinamika Islam Kultural, Pemetaan atas wacana Keislaman Kontemporer (Bandung: Mizan, 2004), 26, 246.

${ }^{16}$ Menurut Abdul Munir Mulkan gelar ini diberikan atas keberhasilannya Al-Ghazali dalam menempatkan pemikiran Islam diluar pemikiran Yunani. Lihat Abdul Munir Mulkan, Mencari Tuhan dan Tujuh Jalan Kebenaran, sebuah esai pemikiran Al-Ghazali, ed, cet 1, (Jakarta: Bumi Aksara, 1992), 8
} 
tahun 450H/1058M di Tus(Sekarang Meshed) ${ }^{17}$ dan dia hidup dimasa peralihan dari abad ke 11 menuju abad ke 12, dan meninggal pada tahun 505H/1111M ditempat yang sama. ${ }^{18} \mathrm{Al}$ - Ghazali menyaksikan kekacauwan politik dan religious yang menimpa ummat Islam. Dilain sisi dia hidup pada paruh kedua masa kekuasaan dinasi Abasisyah, dimana waktu itu kekuasannya sudah terpecah-pecah menjadi beberapa kerajaan kecil yang justru memegang kekuasan efektif dalam suatu kekuasaan. ${ }^{19}$ Daerah kelahiran Al-Ghazali pada waktu itu dipegang oleh dinasti Saljuk, yang berhasil merebut kekuasan dari Abbasiyah tiga tahun menjelang kelahiran beliau.

\section{Konsumsi dan Tujuannya dalam Islam}

Krisis pada pinjaman subprime mortgage di Amerika serikat pada pertengahan 2007, menyentak kesadaran kita semua akan akibatnya yang menjalar ke seluruh penjuru dunia. Pada awal 2008, krisis tersebut meluas dan menjadi pemicu krisis keuangan yang lebih luas mencakup pasar modal dan perbankan. Indonesiapun tak bisa memungkiri krisis ini, dan menjadi salah satu negara yang terkena imbasnya. Dimana indeks harga saham gabungan (IHSG) di Bursa Efek Indonesia (BEI) jatuh secara beruntun, dan akhirnya ditutup selama 3 hari guna mencegah kekacauan dan kejatuhan yang lebih besar. ${ }^{20}$

Dalam al-Qur'an ajaran tentang konsumsi dapat diambil dari kata kulu dan isyrabu terdapat sebanyak 21 kali. Sedangkan makan dan minumlah (kulu wasyrabu) sebanyak enam kali. Jumlah ayat mengenai ajaran konsumsi, belum termasuk derivasi dari akar kata akala dan syaraba selain fi'il amar di atas sejumlah 27 kali. ${ }^{21}$ Seperti halnya pada ayat-ayat berikut:

"Hai sekalian manusia, makanlah yang halal lagi baik dari apa yang terdapat di bumi, dan janganlah kamu mengikuti langkah-langkah

\footnotetext{
${ }^{17}$ Tus adalah salah satu kota di Provinsi Khurasan yang didominasi oleh mayoritas Islam Sunni dan sebagian kecil Islam Syi'ah, serta penduduk yang menganut Kristen. Dan karenanya beliau juga sering disebut dengan Al-Ghazali Al-Khurasain suatu tempat kira-kira 10 Mil dari Naisabur Persia. Lihat Euis Amalia, Sejarah pemikiran Ekonomi Islam, (Depok: Gramata Publishing, 2010), 163

18 Abd Al-Halim Mahmud, Qodiyat at-Tasawuf al-Munqiz min Ad-Dalal, (Kairo: Daar AlMa'arif, tt), h. 26. Lihat juga Al-Imam Hujjah Al-Islam Abi Hamid Muhammad bin Muhammad Al-Ghazali, Almunqiz Min Ad-Dalal, Muhammad Jabir, (ed)(Bairut: al-maktabah Asya'biyah, tt), 21-22, lihat Imam Al-Ghazali, MInhajul Abidin, jalan para ahli ibadah, penerjamah Abu Hamas As-sasaky, (Jakarta: Khatulistiwa Press, 2008), xiii

19 Ibid, Dimyati Ahmad, Teori Keuangan Islam Metodologis Terhadap Teori Keuangan AlGhazali, 22

20 Muhammad Handry Imansyah, Krisis Keuangan di Indonesia Dapatkah Diramalkan?, (Jakarta: PT Elex Media Komputindo), 2009, XXI

${ }^{21}$ Diantara ayat-ayat konsumsi dalam al-Qur'an adalah (QS. Al-Baqarah[2]: 168, 172, 187); (QS. Al-Maidah[5]: 4, 88); (QS. Al-An'am[6] 118, 141, 142); (QS. Al-A'raf[7]: 31, 160, 161); (QS. Al-Anfal[8]: 69); (QS. An-Nahl[16]: 114); (QS. Al-Isra'[17]: 26-28, (QS. Toha[20]: 54, 81); (QS. Al-Hajj[22]: 28, 36; (QS.Al-Mukminun[23]: 51), (QS. Saba[34]: 15); (QS. At-Tur[52]: 19, (QS. Al-Mulk[67]: 15), (QS. Al-Haqqah[69]: 24), (QS. Al-Mursalat[77]: 43, 46).
} 
syaitan; Karena Sesungguhnya syaitan itu adalah musuh yang nyata bagimu"22

"Maka makanlah yang halal lagi baik dari rezki yang Telah diberikan Allah kepadamu; dan syukurilah nikmat Allah, jika kamu Hanya kepada-Nya saja menyembah"23

Pada kedua ayat secara tegas, terdapat prinsip halal dan baik, prinsip ketiadaan mengikuti hawa nafsu, prinsip syukur dan prinsip tauhid. Dengan prinsip-prinsip demikian, maka pola konsumsi seseorang dan juga masyarakat, diarahkan kepada kebutuhan dan kewajiban berdasakan standar-standar prinsip di atas.

"Hai anak Adam, pakailah pakaianmu yang indah di setiap (memasuki) mesjid, makan dan minumlah, dan janganlah berlebih-lebihan. Sesungguhnya Allah tidak menyukai orang-orang yang berlebihlebihan"24

"Katakanlah: "Siapakah yang mengharamkan perhiasan dari Allah yang Telah dikeluarkan-Nya untuk hamba-hamba-Nya dan (siapa pulakah yang mengharamkan) rezki yang baik?" Katakanlah: "Semuanya itu (disediakan) bagi orang-orang yang beriman dalam kehidupan dunia, khusus (untuk mereka saja) di hari kiamat." Demikianlah kami menjelaskan ayat-ayat itu bagi orang-orang yang Mengetahui. ${ }^{25}$

Pada kedua ayat di atas, terdapat prinsip menjauhkan diri dari kekikiran baik pada diri sendiri maupun terhadap orang lain. Demikian pula terdapat prinsip proporsionalitas dalam melakukan aktivitas konsumsi. Dan prinsip pertanggung jawaban dalam setiap aktivitas konsumsi. Parameter kepuasan dalam Islam bukan hanya terbatas pada benda-benda konkrit (materi), tapi juga tergantung pada sesuatu yang bersifat abstrak, seperti amal shaleh yang manusia perbuat. ${ }^{26}$ Kepuasan dapat timbul dan dirasakan oleh seorang manusia muslim ketika harapan mendapat kredit poin dari Allah SWT melalui amal shalehnya semakin besar. Berdasarkan pembahasan taraf kepuasan hidup manusia, penting untuk di bahas perbedaan kebutuhan dan keinginan. Islam memiliki nilai moral yang ketat

${ }^{22}$ QS. Al Baqarah[2]: 168

${ }^{23}$ QS. An-Nahl[16]: 114.

${ }^{24}$ QS. Al-A'raf[7]: 31-32

${ }^{25}$ QS. Al-A'raf[7]: 31-32

${ }^{26}$ Hal Ini dimaksudkan, bahwasanya kepuasan yang tergantung pada sesuatu yang bersifat abstrak seperti amal Shaleh, merupakan sebuah pekerjaan yang apabila dilakukan tidak menyebabkan dan mengakibatkan kemidhoratan, apabila dilakukan akan diperoleh manfaat dan kesesuaian. Bustanudin Agus, Islam dan Ekonomi: Suatu tinjauan Sosiologi Agama,(Padang: Andalas University Press, 2006), 75-76 
dalam memasukkan "keinginan" (wants) dalam motif aktifitas ekonomi. Mengapa? Dalam banyak ketentuan perilaku ekonomi Islam, motif "kebutuhan" (needs) lebih mendominasi dan menjadi nafas dalam roda perekonomian dan bukan keinginan. Kebutuhan (needs) didefinisikan sebagai segala keperluan dasar manusia untuk kehidupannya. Sementara keinginan (wants) didefinisikan sebagai desire (kemauan) manusia atas segala hal. ${ }^{27}$ Ruang lingkup keinginan lebih luas dari kebutuhan; sebagai contoh sederhana menggambarkan perbedaan kedua kata ini dapat dilihat dalam perilaku konsumsi pada air untuk menghilangkan dahaga. Kebutuhan seseorang untuk menghilangkan dahaga mungkin cukup dengan segelas air putih, tapi seseorang dengan kemampuan dan keinginannya dapat saja memenuhi kebutuhan itu dengan segelas wishky, yang tentu lebih mahal dan lebih memuaskan keinginan.

Perekonomian Islam berlandaskan kepada al-qur'an dan hadits sebagai panduan yang memberikan petunjuk-petunjuk yang sangat jelas kepada umat Islam. ${ }^{28}$ Berbagai hal tercakup di dalamnya tidak terkecuali mengenai konsumsi. Dengan berdasar pada petunjuk-petunjuk tersebut, maka kegiatan ekonomi dalam Islam mempunyai tujuan agar manusia mencapai kejayaan (al-falah) di dunia dan akhirat. ${ }^{29}$ Segala sesuatu sumber daya yang ada di bumi ini diciptakan untuk manusia. Dengan demikian maka konsumsi dalam Islam juga bertujuan untuk kepentingan dunia dan akhirat. Hal ini tercermin dalam Firman Allah sebagai berikut:

"Dan dia (menundukkan pula) apa yang dia ciptakan untuk kamu di bumi ini dengan berlain-lainan macamnya. Sesungguhnya pada yang demikian itu benar-benar terdapat tanda (kekuasaan Allah) bagi kaum yang mengambil pelajaran." 30

Dalam hal pemenuhan kebutuhan seseorang dalam kegiatan konsumsi, Islam tidak mengakui kegemaran materialistis semata-mata dari pola konsumsi modern. Etika Ilmu ekonomi Islam berusaha untuk mengurangi kebutuhan material yang luar biasa untuk menghasilkan energi manusia dalam mengejar cita-cita spiritualnya. ${ }^{31}$ Hal ini akan menentukan bagaimana seorang muslim dalam pola konsumsinya, seperti halnya anjuran Rasulullah agar selalu berakhlak mulia. Dengan demikian maka seorang muslim akan menafkahkan hartanya untuk kebaikan, menjauhi diri dari sifat kikir, serta akan bersikap sederhana

27 Lebih jelasnya manusia tidak hanya ditawari apa yang mereka butuhkan (What They Needed), melainkan pula oa yang mereka harapkan (What They Desired). Dengan demikian "want" berubah secara aktif menjadi "Needs", apa yang semula sekedar menjadi keinginan berubah menjadi yang dibutuhkan. Haryanto Soedjatmiko, Saya berbelanja maka saya ada, ketika Konsumsi dan Desain Menjadi Gaya Hidup Konsumeris, (Yogyakarta: Jalasutra, 2008), 19

28 Muhammad dan Lukman Fauroni, Visi Al-Qur'an Tentang Etika dan Bisnis, (Jakarta: Selemba Diniyah, 2002), 3-4

${ }^{29}$ Ibid, Pusat Pengkajian dan Pengembangan Ekonomi Islam, Ekonomi Islam, 2-3

30 (QS an-Nahl: 13)

31 Muhammad, Prinsip-Prinsip Ekonomi Islam, (Yogyakarta: Graha Ilmu, 2007), 81-82 


\section{Imam Al-Ghazali dan Konsumsi: Tujuan, Konsepsi dan Batasannya}

Banyak pakar yang memberikan solusi terhadap krisis ekonomi yang terjadi. Meskipun terdapat perbedaan, tetapi pada umumnya kunci dari solusi krisis adalah menghilangkan sistem bunga (riba) dalam ekonomi. Diantara mereka adalah sebagai berikut: ${ }^{32}$ Menurut Al-Ghazali teori Ekonomi yang dibangun berdasarkan syariah Islam, memiliki perbedaan yang mendasar dengan teori konvensional. Perbedaan ini terletak pada landasan filosofisnya, dalam hal ini AlGhazali mendefinisikan bahwa masalah Ekonomi yang terjadi karena adanya keinginan manusia yang tidak terbatas, sementara islam memandang bahwa keinginan manusia terbatas. Sebagaimana firman Allah Swt:

$$
\text { إن كل شيء خلقه بقدر }
$$

"Sesungguhnya telah kami ciptakan segala sesuatu alam ukuran yang setepat-tepatnya"33

Perbedaan cara pandang juga menentukan hasil akhir sebuah konsep. Misalnya saja konsep dasar tentang tujuan manusia diciptakan dan bagaimana manusia mencapai tujuan tersebut?. dalam menjawab pertanyaan yang sangat fundamental tersebut Al-Ghazali telah meletakan landasan yang benar tentang falsafah ekonomi islam. Menurut beliau tujuan hidup seorang muslim adalah mencapai keselamatan di Akhirat. ${ }^{34}$ Adapaun salah satu sarana untuk mencapai tujuan akhirat menurut AL-Ghazali adalah dengan mencari nafkah (harta yang halal dan tidak berlebihan), serta melalui sarana yang berdasarkan syariah dalam menjalankan aktifitas ekonomi (Pola Konsumsi). Sebagaimana dinyatakan, ${ }^{35}$

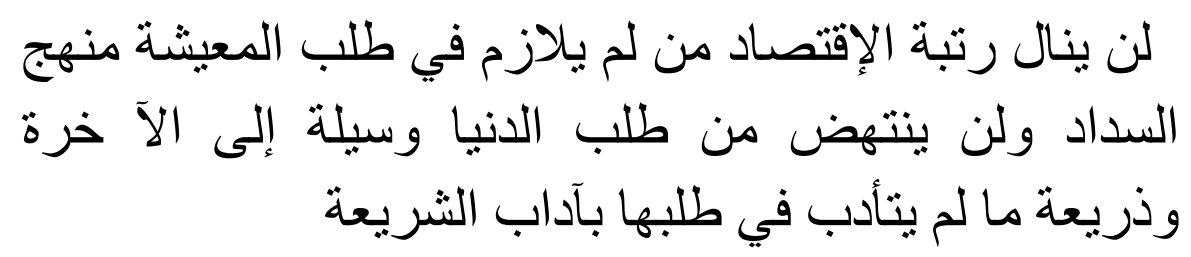

Disini tampak jelas bahwa antara akidah islam (akhirat) dengan persoalan kehidupan ekonomi (dunia). Mempunyai hubungan yang sangat erat, yaitu hubungan antara sarana ekonomi (konsumsi) dan tujuan (alwasilah wal ghayah).

32 Karnaen A. Putraatmadja dan Hendri Tanjung, Bank Syari'ah, Teori, Praktek dan Peranannya, (Jakarta: Celestial Publishing, 2007), 165.

${ }^{33}$ Al-Qur'an Surat Al-Qomar: 49

34 Ibid, Al-Ghazali, Ihya Ulumu Ad-Din, Jilid III, 215. Ungkapan Al-Ghazali tentang bagaimana mendapatkan tujuan hidup sesuai dengan kemauan Allah, disini beliau banyak mengungkap tantang keberadaan dunia menuju akhirat.

${ }^{35}$ Ibid, Al-Ghazali, Ihya Ulumu Ad-Din, Jilid II, 62 
Oleh karena itu segala macam aktifitas ekonomi menjadi suatu yang amat penting seperti halnya konsumsi dalam kehidupan manusia bahkan bagi keselamatan akidah itu sendiri. Pola konsumsi bagi manusia merupakan kebutuhan yang sifatnya primer bukan sekunder, di nomor duakan, atau dimarjinalkan. Dalam pola konsumsi, Al-Qur'an secara tegas menjelaskan bahwa manusia dapat memanfaatkan segala ciptaan Allah dibumi sebagai bahan konsumsinya. Hanya saja pemenuhan konsumsi itu harus dijalankan secara wajar dan seimbang. Tidak berlebihan atau berlaku kikir. ${ }^{36}$ Pola konsumsi yang melebihi batas kewajaran dalam Al-Qur'an diistilahkan dengan tabdhir dan israf. ${ }^{37}$ Dengan demikian maka jelaslah bahwa pada hakekatnya konsumsi adalah suatu pengertian yang positif. Dengan mengurangi pemborosan yang tidak perlu, islam menekankan perilaku mengutamakan kepentingan orang lain, yaitu pihak konsumen. Sikap moderat dalam prilaku konsumen ini kemudian menjadi logis dari gaya konsumsi Islam. Yaitu sifatnya nisbi dan dinamik. ${ }^{38}$

Konsumsi memang memiliki urgensi sangat penting dalam semua kegiatan ekonomi, karena manusia tidak dapat hidup tanpa konsumsi. Oleh karena itu kegiatan ekonomi harus mengarah terhadap pemenuhan tuntutan konsumsi manusia. jika hal ini diabaikan berarti juga mengabaikan kehidupan manusia dan niscaya kehidupan manusia tidak akan pernah sempurna. Al-Ghazali sangat memahami urgensi konsumsi dan keniscayaannya dalam kehidupan, sehingga pemikiran ekonomi Al-Ghazali tentang konsumsi dapat dilihat sebagai berikut: pertama, konsep Al-Ghazali tentang pemenuhan kebutuhan banyak menfokuskan kepada terpenuhnya kebutuhan manusia secara lahiriah dan bathiniah. Sehingga aspek ini merupakan salah satu hal yang penting dalam proses berkehidupan, dan dituntut untuk mengutamakan akhirat dari pada dunia ${ }^{39}$ Kedua, Al-Ghazali berpendapat bahwa setiap orang bertanggung jawab atas pemenuhan kebutuhannya masing-masing dan harus mengusahakannya semaksimal mungkin (tentuanya sesuai kebutuhan serta dengan norma dan etika Islam). ${ }^{40} \mathrm{Ketiga}$, bahwa Al-Ghazali selalu menekankan etika dan norma dalam mengkonsumsi yang halal dan tayyib serta menjauhi yang haram. ${ }^{41}$ Sebagai bentuk dari konsisten masyarakat dalam memenuhi kebutuhannya, Al-Ghazali telah membagi prioritas pemenuhan kebutuhan dalam tiga bagian:

\footnotetext{
${ }^{36}$ Al-Qur'an, 6 ayat 141

${ }^{37}$ Sekilas dua istilah ini mengarah pada suatu pengertian pemborosan, akan tetapi sebenarnya, kedunaya memiliki spesifikasi makna tersendiri. Tabdhir bearti menggunakan harta untuk tujuan yang dilaran, missal penyuapan, judi dan lain-lain. Sedangkan ishraf bearti peggunaan harta secara berlebihan, baik mengenai kebutuhan yang diperbolehkan, misalnya: makanan, pakaian dan tempat tinggal, maupun menyangkut perbuatan yang dianjurkan missal Shodaqoh. Lihat : Monzer Kahf, Ekonomi Islam : Telaah Analitik terhadap fungsi system Ekonomi Islam, Terj, Machsun Husein, (Yogyakarta: Pustaka Pelajar, 1995), 28

${ }^{38}$ Mannan, Teori dan praktek, 50

${ }^{39}$ Ibid, Al-Ghazali, Ihya Ulumu ad-Din, Jilid III, 221

${ }^{40}$ Ibid, Al-Ghazali, Ihya Ulumu ad-Din, Jilid II, 61-67

${ }^{41}$ Ibid, 95
} 
1) Daruriyyah, yaitu kebutuhan tingkat dasar atau kebutuhan primer

2) Hajjiyah, yaitu kebutuhan pelengkap/ penunjang atau sekunder

3) Tahsiniyyah, yaitu kebutuhan akan kemewahan atau kebutuhan tersier

Namun perlu diingat bahwa konsep keperluan dasar dalam Islam sifatnya tidak statis, artinya keperluan dasar pelaku ekonomi bersifat dinamis merujuk pada tingkat ekonomi yang ada pada masyarakat. Pada tingkat ekonomi tertentu sebuah barang yang dulu dikonsumsi akibat motifasi keinginan, pada tingkat ekonomi yang lebih baik barang tersebut telah menjadi kebutuhan. ${ }^{42}$ Dengan demikian parameter yang membedakan definisi kebutuhan dan keinginan tidak bersifat statis, ia bergantung pada kondisi perekonomian serta ukuran kemashlahatan. Dengan standar kamashlahatan, konsumsi barang tertentu dapat saja dinilai kurang berkenan ketika sebagian besar ummat atau masyarakat dalam keadaan susah.

\section{Gambar 4.1.: Teori Konsumsi Al-Ghazali}

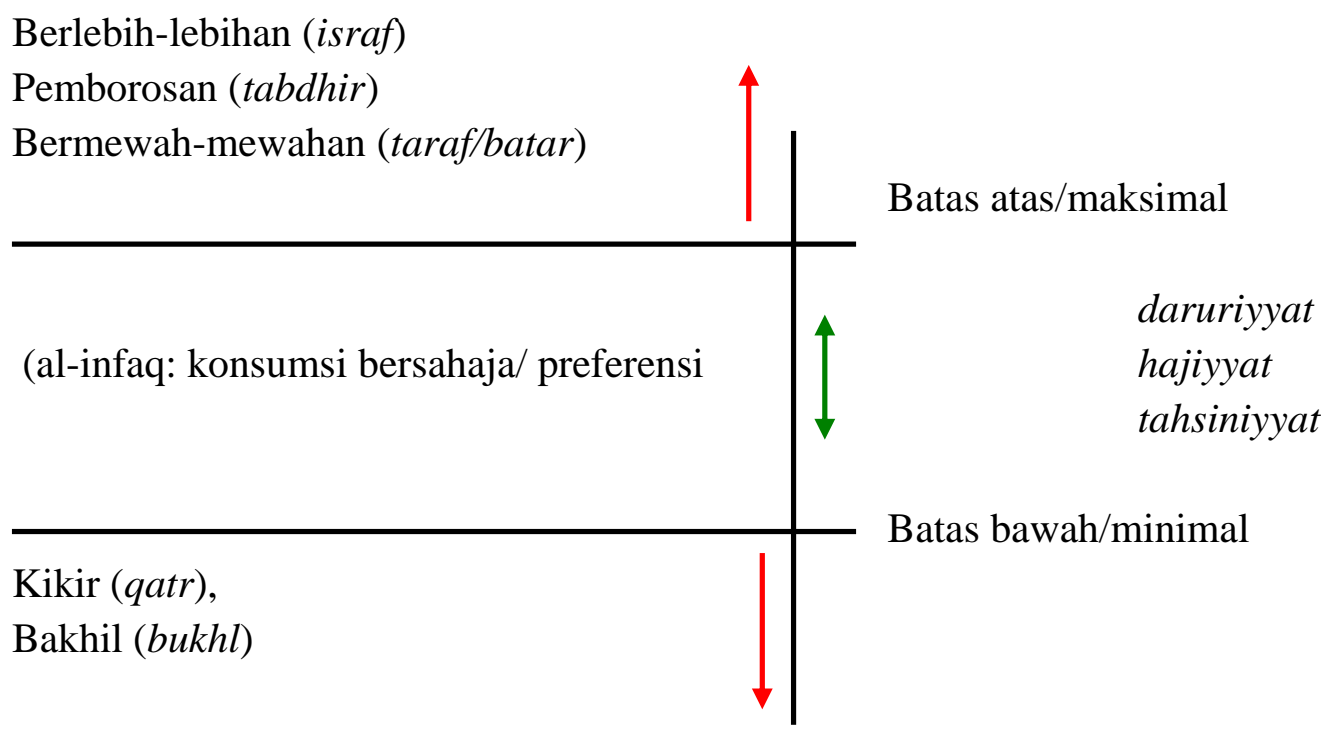

\section{Penutup}

Pemikiran ekonomi Al-Ghazali, khususnya dalam bidang Konsumsi dibangun atas landasan kokoh yang merupakan integrasi antara aspek rasional dan agama

\footnotetext{
${ }^{42}$ Sudono Sukirno, Pengantar Makro Ekonomi, (Jakarta: Raja Grafindo Persada, 1997), 5
} 
yang diramu sedemikian rupa. Al-Ghazali meletakan landasan hidup seorang muslim adalah dengan mencapai tujuan keselamatan akhirat. Adapun salah satu cara untuk mencapai tujuan akhirat dengan menjalankan aktifitas konsumsi berdasarkan syariah Islam. Dengan demikian, tampak jelas bahwa antara akidah Islam (akhirat) dengan persoalan kehidupan ekonomi (dunia) mempunyai hubungan yang sangat erat, yaitu hubungan antara sarana ekonomi (konsumsi) dan tujuan (wasliah wal ghoyah). Secara singkat gambaran konsep konsumsi dapat dijelasakan sebagai berikut: Asumsi dasar yang dipakai Ghozali adalah bahwa pandangan Islam dalam setiap aspeknya adalah demi ridho Allah dan kebaikan dunia akhirat. Dalam kosep ini keridhoan allah akan tercipta apabila pemenuhan kebutuhan banyak menfokuskan kepada terpenuhnya kebutuhan manusia secara lahiriyah dan bathiniyah(tentunya sesuai dengan etika dan norma islam), sehingga aspek ini merupakan salah satu hal penting dalam proses kehidupan. Dari asumsi dasar tersebut al-Ghazali secara konsisten menjabarkan tingkatan dalam konsumsi, yaitu had ad-dhorurah, had al-hajah dan had attana'um. Diantara tiga tingkatan ini, beliau sendiri lebih menyukai berada diantara had ad-dharurah (kebutuhan Primer) dan had al-hajah (kebutuhan Sekunder) yaitu tahsiniyah. Hal ini dikarnakan tahsiniyah menghendaki kehidupan yang indah dan nyaman didalamnya, yang mana terdapat provisi dalam syariah yang dimaksudkan untuk mencapai pemanfaatan yang lebih baik, keindahan dan simplikasi dari daruriyah dan hajiyah.

Di sisi lain, penelaahan Al-Ghazali terhadap teori konsumsi memberikan konsep unik tentang batasan-batasan serta arahan positif dalam berkonsumsi, diantaranya: pertama, sifat dan cara. Bagi pelaku ekonomi muslim semestinya sensitive terhadap sesuatu yang dilarang dalam Islam. Seorang muslim hanya mengkonsumsi produk-produk yang jelas halal dan menghindari sejauh mungkin yang haram. Kedua, batasan dalam hal kuantitas dan ukuran konsumsi, AlGhazali memberikan arahan agar tidak berlaku kikir yakni terlalu menahan harta dan juga sebaliknya mengeluarkan harta secara berlebih-lebihan diluar kewajaran sesuai dengan faktor kebutuhan. Ketiga, dalam hal perilaku, al-Ghazali menekankan pentingnya niat dalam melakukan konsumsi, sehingga tidak kosong dari makna etika. Namun dalam analysis ekonomi keperluan dasar manusia bersifat tidak statis, artinya keperluan dasar pelaku ekonomi bersifat dinamis merujuk pada tingkat ekonomi yang ada pada masyarakat. Meskipun demikian Al-Ghazali tidak menutup mata bahwa pada tingkat ekonomi tertentu sebuah barang yang dulu dikonsumsi akibat motivasi keinginan, pada tingkat ekonomi yang lebih baik barang tersebut telah menjadi kebutuhan. Dengan demikian parameter yang membedakan definisi tingkat konsumsi manusia tidak bersifat statis, ia bergantung pada kondisi perekonomian serta ukuran kemaslahatan. Karena itu Al-Ghazali memprioritaskan Etika sebagai asas dasar dalam mengukur tingkat pola konsumsi mansyarakat yang tentunya berdasarkan nilai-nilai islam, hal inilah yang dimaksud Al-Ghazali dengan Homo Islamicus. Dalam konteks 
yang demikian Teori Konsumsi Al-Ghazali sangat relevan utuk dijadikan sebagai salah satu acuan untuk mewujudkan terciptanya pola konsumsi Islami yang berlandaskan nilai-nilai ibadah dalam berekononmi, mengedepankan kemaslhatan akhirat dan tidak meninggalkan kemaslahatan dunia.

\section{Daftar Pustaka}

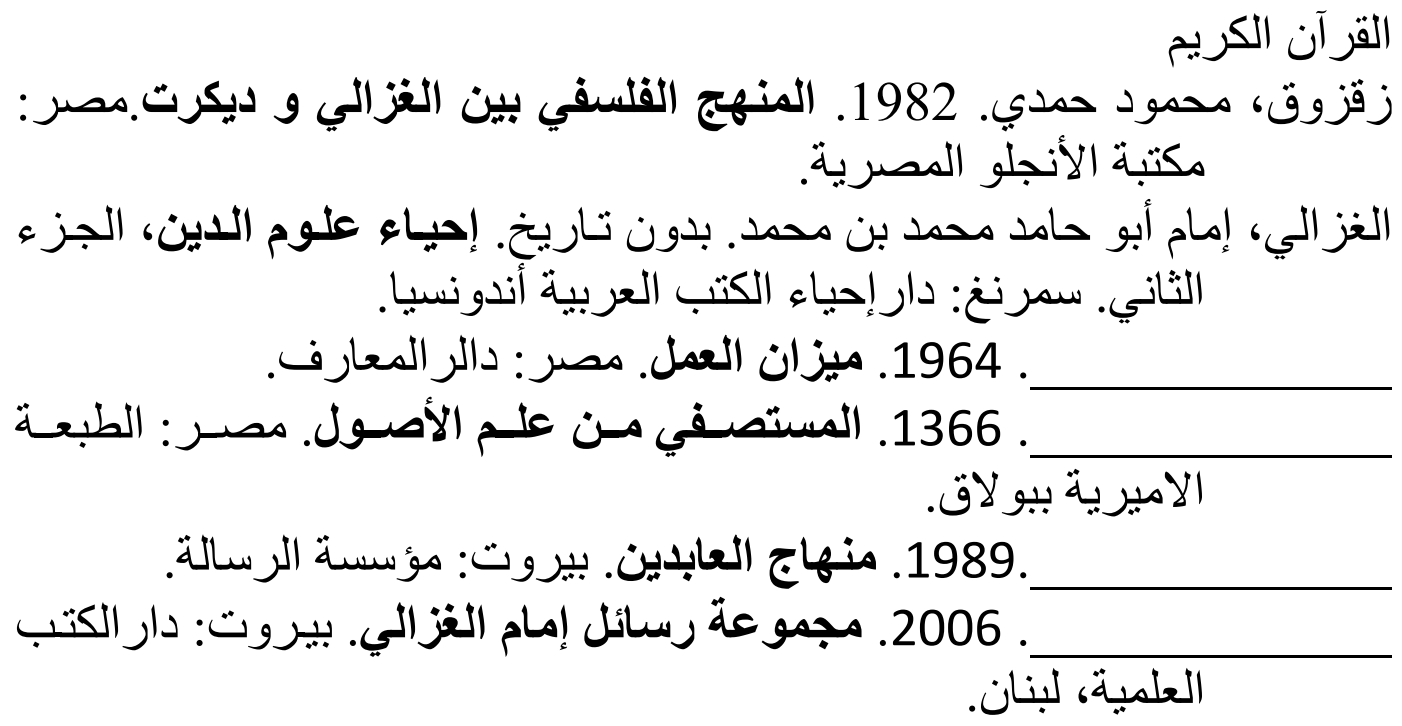

Ghanzafar, S. Mohammad dan Abdul Azim Silahi. Economy Thought of AlGhazali. Jeddah, Saudi Arabia: Islamic Economic Research Series King Abdul Aziz University, Scientific Publishing Centre.

Najatullah Siddiqi, Muhammad. 1980. Muslim Economic Thinking; A. Survey of Contempory Literature. United Kingdom: International Centre for

Research in Islamic Economic King Abdul Aziz University and The Islamic Foundation.

Umaruddin, Muhammad. 1996. The Ethical Philosophy of Al-Ghazali, New Delhi: Aligar Muslim Univeristy, Adam Publiher.

Al-Ghazali, Imam. 2008. Minhajul Abidin, Alih Bahasa oleh Abu Hamas AsSasaky dengan judul Minhajul Abidin Jalan Para Ahli Ibadah. Jakarta: Khatulistiwa Press.

Abdul Quasem, Muhammad. 1988. Etika Al-Ghazali, alih bahasa oleh: J. Mahyudin. Bandung : Penerbit Pustaka.

Baudrillard, Jean. 2004. Masyarakat Konsumsi, Alih bahasa dari La Societe de Consummation, Oleh : Wahyunto. Jakarta: Kreasi Wacana.

Dimyati, Ahmad. 2008. Teori Keungan Islam: Rekontruksi Metodologis Terhadap Teori Keuangan Al-Ghazali. Yogyakarta: UII Press.

Faishal, Badroen. 2007. Etika Bisnis Dalam Islam. Jakarta: Kencana. 
Haidar Naqfi, Syed Nawab. 2003. Islam Economics and society, ditarjamahkan oleh M. Saiful dan Muhammad Ufuqil Mubin dengan Judul, Menggagas Ilmu Ekonomi Islam. Yogyakarta: Pustaka Pelajar.

Kahf, Monzer. 1995. The Islamic Economy : Analytical of the Functioning of the Islamic Ecomomic System, Alih bahasa oleh: Machnun Husein. Yogyakarta: Pustaka Pelajar.

Karim, Adiwarman. 2004. Sejarah Pemikiran Ekonomi Islam, edisi II. Jakarta: PT Grasindo Persada.

Muhammad \& Lukman Fauroni. 2002. Visi Al-Qur'an Tentang Etika dan Bisnis. Jakarta: Selemba Diniyah. dan Alimin. 2004. Etika \& Perlindungan Konsumen Dalam Ekonomi Islam. Yogyakarta: BPFE Fakultas Ekonomi UGM. 2002. Etika Bisnis Islam. Yogyakarta: Akademi Manajemen Perusahaan YKPN.

Qardhawi, Yusuf. 1995. Peran Nilai dan Moral dalam Perekonomian Islam. Jakarta : Rabbani Press.

Quasem, Abdul. 1998. Etika Al-Ghazali Etika Majemuk Didalam Islam, Terjemahan J. Mahyuddin, dari Judul asli The Ethics of Ghazal: A Compoit Ethic of Islam. Bandung: Pustaka.

Rahman, Afzalur. 2007. Qur'anic Science, alih bahasa oleh: Taufik Rahman, dengan Judul Ensiklopediana Ilmu Dalam Al-Qur'an: Rujukan terlengkap Isyarat-isyarat ilmiah dalam Al-Qur'an. Bandung: PT Mizan Pustaka.

Rohman, Abdur. 2010. Ekonomi Al-Ghazali (Menelusuri Konsep Ekonomi AlGhazali dalam Ihya Ulumu Ad-Din). Surabaya: PT Bina Ilmu. 